\title{
BIFIDOBACTERIA IN THE INTESTINAL TRACT OF INFANTS: AN IN-VITRO STUDY
}

\author{
C. L. Bullen And P. V. Tearle \\ Public Health Laboratory, Luton and Dunstable Hospital, Luton, Beds
}

\section{Plate XXIV}

IT is well known that the nature of the milk fed to new-born infants greatly influences the physico-chemical and microbiological properties of their faeces. The most prominent features of the faeces of breast-fed infants in comparison with those of bottle-fed infants are a preponderance of bifidobacteria, a low $p \mathrm{H}$ and a virtual absence of putrefactive organisms, and it has been customary to regard this triad as sequentially related.

The results of studies in vivo indicate that although $p \mathrm{H}$ does influence the nature of the bacterial flora, of much greater importance in this respect is the presence of an acetic acid and acetate buffer (Willis et al., 1973; Bullen, Tearle and Willis, 1976).

The aim of the present study was to determine the principal source of acetic acid in infant faeces and the effect of both acetic acid and of an acetic acid and acetate buffer on the growth of certain common faecal bacteria and enteric pathogens.

\section{MATERIALS AND METHOD}

Organisms. Bacteroides fragilis, two laboratory isolates; bifidobacteria, six laboratory, isolates; Clostridium paraputrificum, two laboratory isolates; Clostridium perfringens two laboratory isolates; Escherichia coli, six laboratory isolates including enteropathogenic serotypes 027, 0111, 0125, 0126; Pseudomonas aeruginosa, strains NCTC 10662 and 10701; Salmonella typhimurium, two laboratory isolates; Shigella sonnei, two laboratory isolates; Streptococcus faecium, five laboratory isolates; Vibrio cholerae biotype El Tor, one laboratory strain.

The laboratory strains were isolated from the faeces of infants except for the strains of $C$. perfringens, Salm. typhimurium, Shig. sonnei and V. cholerae El Tor, which were isolated from older patients.

Acetate buffers. A series of nine acetate buffers in the range of $p \mathrm{H} \mathrm{3.8-6.2} \mathrm{were} \mathrm{prepared}$ as described by Cruickshank et al. (1975).

$V L G$ medium (Beerens, et al., 1963). This fluid medium, which contains $1 \%$ glucose, was used in $20-\mathrm{ml}$ aliquots in Universal containers for the production of acetic acid by bacterial cultures.

Modified reinforced clostridial medium $(R C M)$. This was the Oxoid CM 149 formulation (Oxoid Manual, 1973) from which soluble starch, sodium acetate, and agar were omitted. It formed the nutrient basis of acetate-buffered RCM and unbuffered RCM.

Acetate-buffered RCM. Modified Reinforced Clostridial Media buffered at nine different $p \mathrm{H}$ values over the range of $3 \cdot 8-6 \cdot 2$ were prepared by adding the basic ingredients to aliquots

Received 19 Nov. 1975; revised version accepted 13 Feb. 1976.

J. MED. MICROBIOL.—VOL. 9 (1976) 


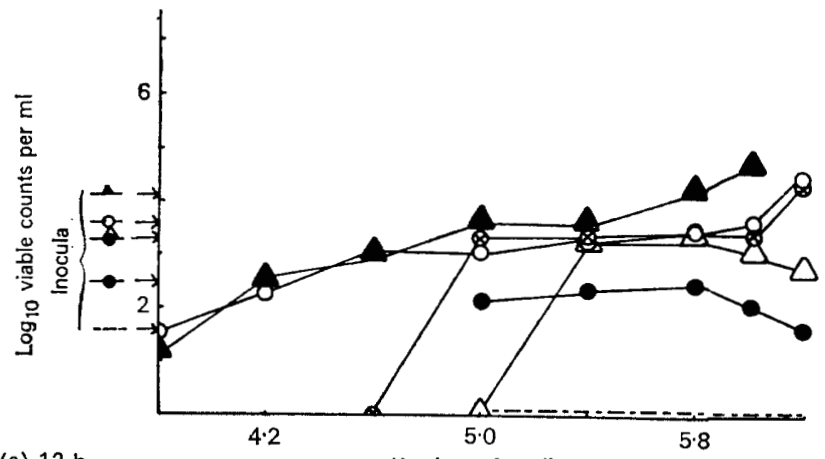

(a) $12 \mathrm{~h}$

$\mathrm{pH}$ values of medium

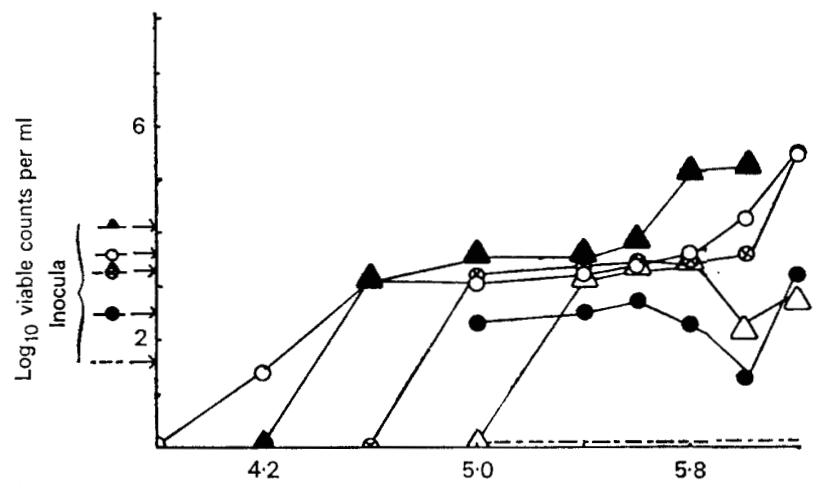

(b) $24 \mathrm{~h}$

$\mathrm{pH}$ values of medium

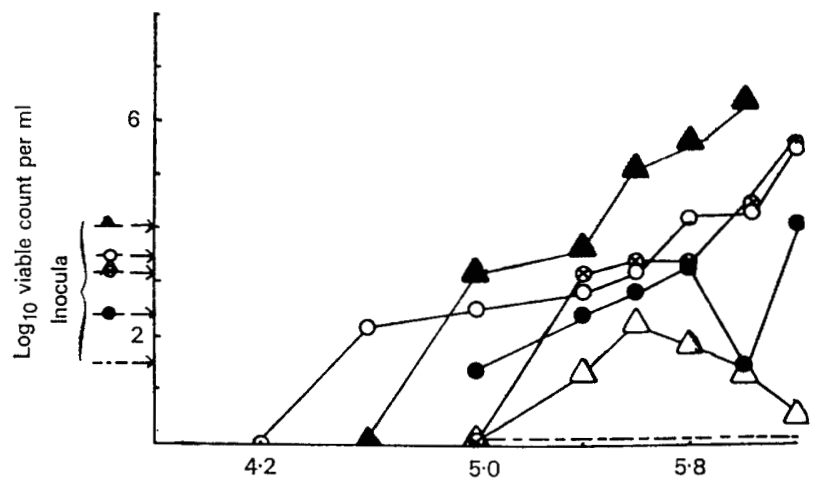

(c) $48 \mathrm{~h}$

$\mathrm{pH}$ values of medium

Fig. 4 ( $a, b$ and $c)$.-Average of mean viable counts of gram-negative organisms in buffered medium after 12,24 and 48 hours' incubation: $\bigcirc-\bigcirc \mathrm{E}$. coli;

Pseudomonas aeruginosa $\otimes-\otimes$ Salmonella typhimurium; V. cholerae El Tor. 


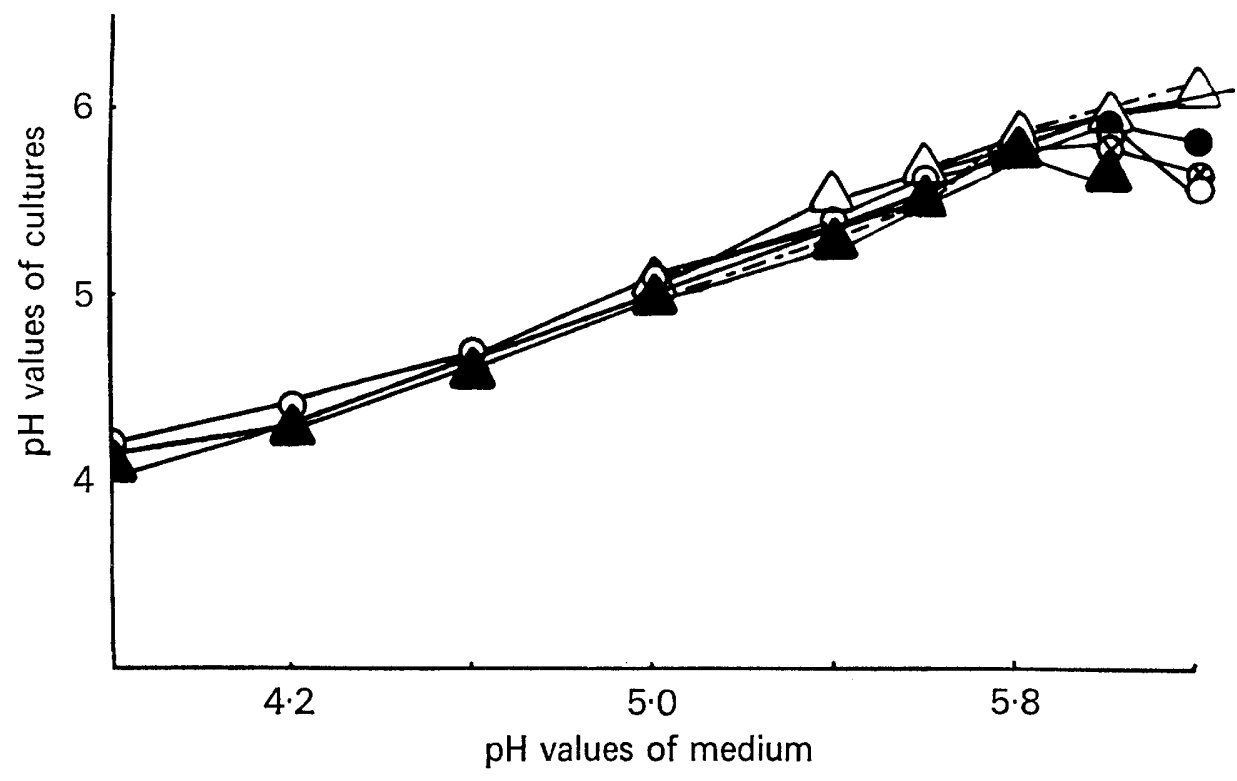

FIG. 5.-Initial $p \mathrm{H}$ of buffered medium: $\_$, compared with the $p \mathrm{H}$ values of 48 -h cultures of gramnegative organisms: Salm. typhimurium;

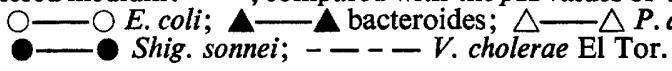

of each of the acetate buffers. The medium at each different $p \mathrm{H}$ value was dispensed in $15-\mathrm{ml}$ volumes in Universal containers; the bottles were steamed once for $30 \mathrm{~min}$.

Unbuffered RCM. Modified Reinforced Clostridial Media at the same $p \mathrm{H}$ values as the buffered media were prepared by dissolving the basic RCM ingredients in distilled water and adjusting the $p \mathrm{H}$ with glacial acetic acid. The medium at each of the nine different values was dispensed in 15-ml volumes in Universal containers; the bottles were steamed once for $30 \mathrm{~min}$.

Acetate-buffered RCM and unbuffered RCM media were used to study the effect of $p \mathrm{H}$, of acetic acid and of acetate buffer on the growth of the various bacterial species.

Determination of volatile products of bacterial metabolism. Strains of bifidobacteria, $E$. coli and Strept. faecium were examined for volatile products of metabolism. Five-day-old anaerobic cultures in VLG medium were extracted with $1.0 \mathrm{ml}$ of di-ethyl ether before and after acidification with $50 \%(\mathrm{v} / \mathrm{v})$ sulphuric acid, and the extracts were analysed by gas-liquid chromatography as outlined by Holdeman and Moore (1972).

Effect of $\mathrm{pH}$ on bacterial growth under buffered and unbuffered conditions. A suspension of each organism was made in $0 \cdot 15 \mathrm{M} \mathrm{NaCl}$ from $24 \mathrm{~h}$ cultures on solid media. A volume of $0.05 \mathrm{ml}$ of suspension was taken to inoculate each $15-\mathrm{ml}$ aliquot in the set of buffered and unbuffered RCM media, which were then incubated anaerobically in an atmosphere containing $90 \%$ hydrogen and $10 \%$ carbon dioxide, at $37^{\circ} \mathrm{C}$ for $48 \mathrm{~h}$. Strains of $P$. aeruginosa were incubated aerobically. The number of bacteria in the inoculum was estimated by the method of Miles, Misra and Irwin (1938) for each strain. Estimations of $p \mathrm{H}$ and the total viable count were made on all cultures at 12-hourly intervals; the $p \mathrm{H}$ of all uninoculated media was checked prior to inoculation and after incubation.

Total viable counts. These were performed by the method of Miles, Misra and Irwin (1938), all counts being performed in triplicate and the mean for each strain determined. MacConkey's agar was used for counting Enterobacteriaceae, horse-blood agar for the clostridia, bacteroides and streptococci, and glucose $(1 \%)$ horse-blood agar for the bifidobacteria. Plates were incubated for $48 \mathrm{~h}$ under appropriate atmospheric conditions. 


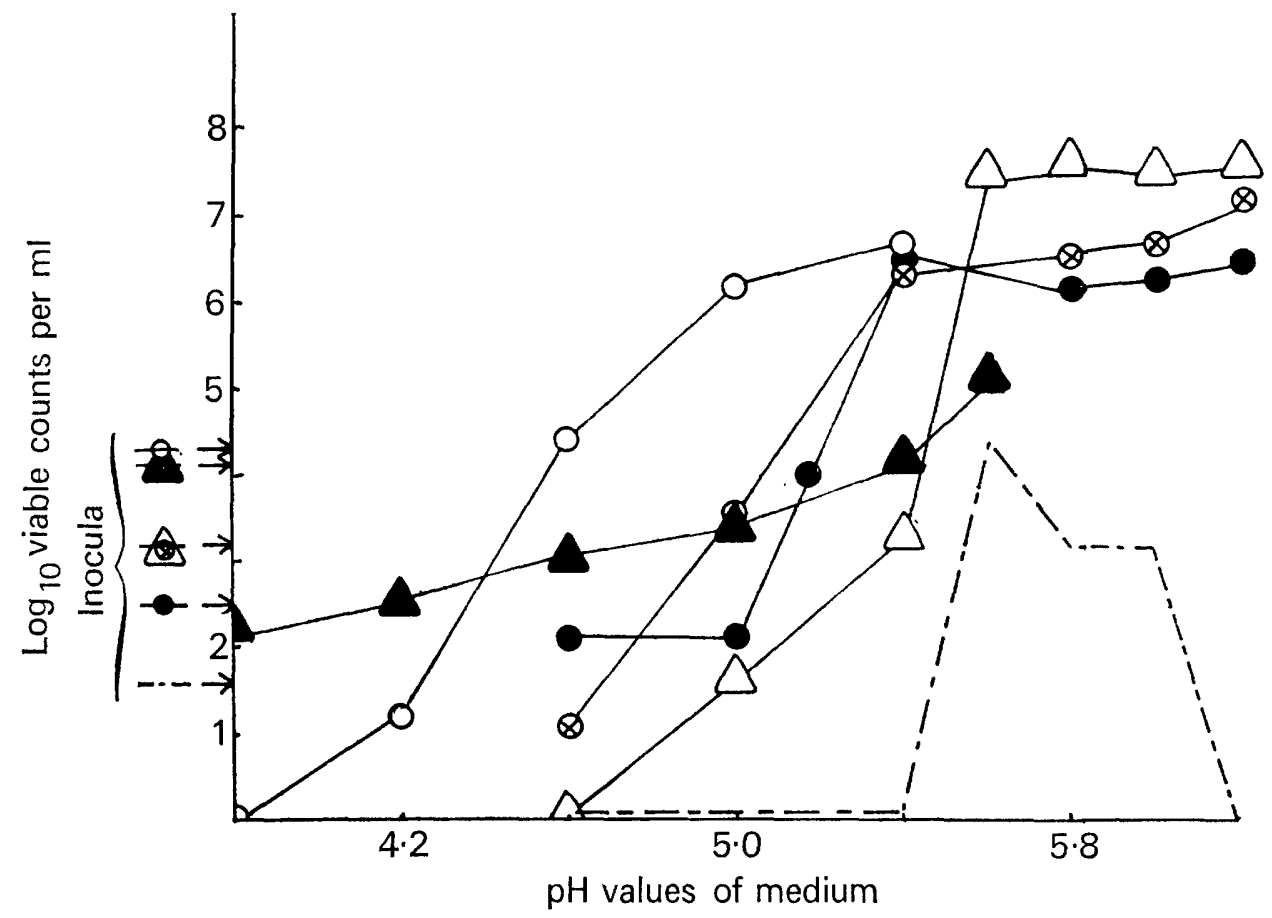

FIG. 6.-Average of mean viable counts of gram-negative organisms in unbuffered medium after 24 hours'incubation: $\bigcirc-O E$. coli; $\triangle-\Delta$ bacteroides; $\triangle \longrightarrow \triangle P$. aeruginosa; $\otimes-\otimes$ Salm. typhimurium; - Shig. sonnei; - - - V. cholerae El Tor.

\section{RESULTS \\ Production of acetate buffer}

The chromatograms from the cultures of bifidobacteria, E. coli and Strept. faecium show that although all three saccharolytic organisms produced signifcant amounts of acetic acid, an acetate buffer was developed only by bifidobacteria and $E$. coli; strains of bifidobacteria were much more active in this respect (figs. 1-3).

\section{Growth of gram-negative organisms in acetate-buffered media}

Viable counts. The acetate-buffered medium was bactericidal below $p \mathrm{H}$ 5.0 for all the gram-negative organisms examined. The effect became more pronounced as the incubation time increased. Between $p \mathrm{H} 5.0$ and 5.8 the buffer was strongly bacteristatic, an effect that was most obvious at $24 \mathrm{~h}$, and thereafter the organisms, except for $P$. aeruginosa, began to grow at a retarded rate. The growth of bacteroides was least affected by the buffer, while $V$. cholerae El Tor showed no growth at any time (fig. $4(a),(b),(c))$.

$p H$ values. Bacterial cultures in the buffered media reached $p \mathrm{H}$ values that reflected the bactericidal and bacteristatic effects of the buffer. After 24 and 48 hours' incubation in media with an initial $p \mathrm{H}$ in the range 5.8-6.2, in which 


\section{BIFIDOBACTERIA IN THE INTESTINE OF INFANTS}

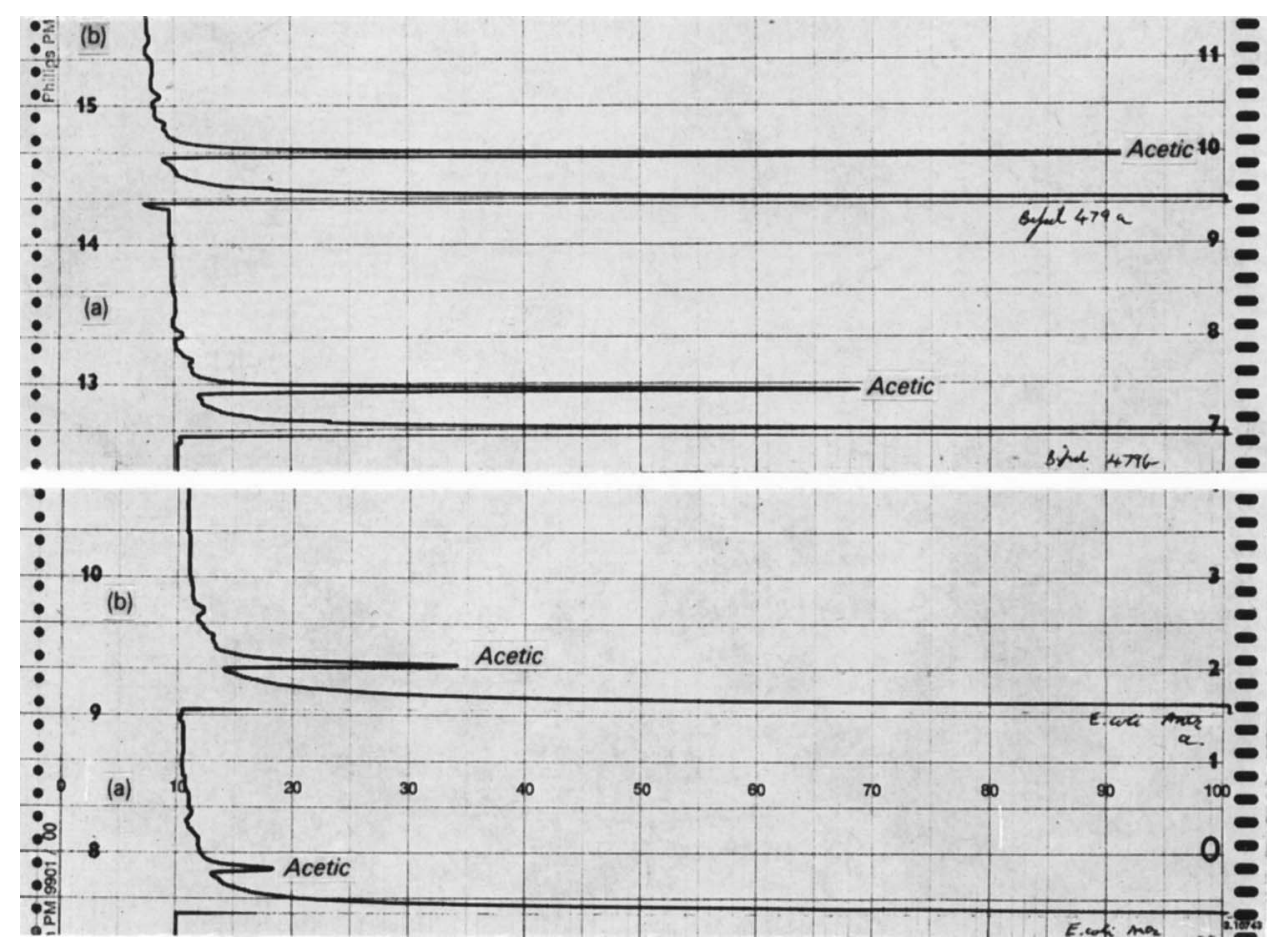

Figs. 1 (top) and 2 (bottom).-Chromatograms from broth cultures of Lactobacillus bifidus, fig. 1, and Escherichia coli, fig. 2: (a) acetic acid before acidification; $(b)$ acetic acid after acidification. The difference between the two curves represents?thelpresence of acetate in the two

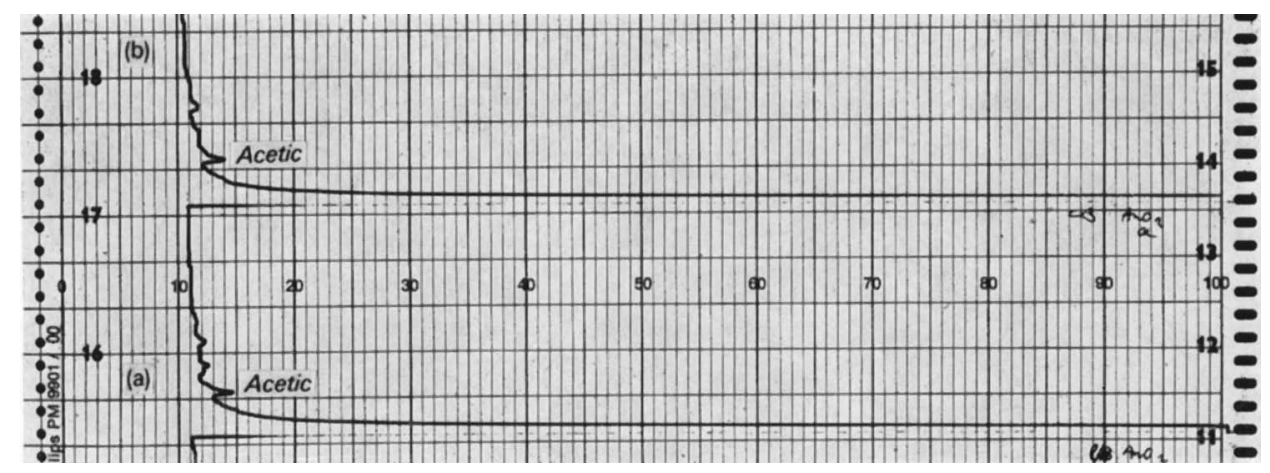

FIG. 3.-Chromatograms from a broth culture of Streptococcus faecium: (a) acetic acid present in the culture before acidification; $(b)$ the same acetic acid curve after acidification, indicating no acetate present. 


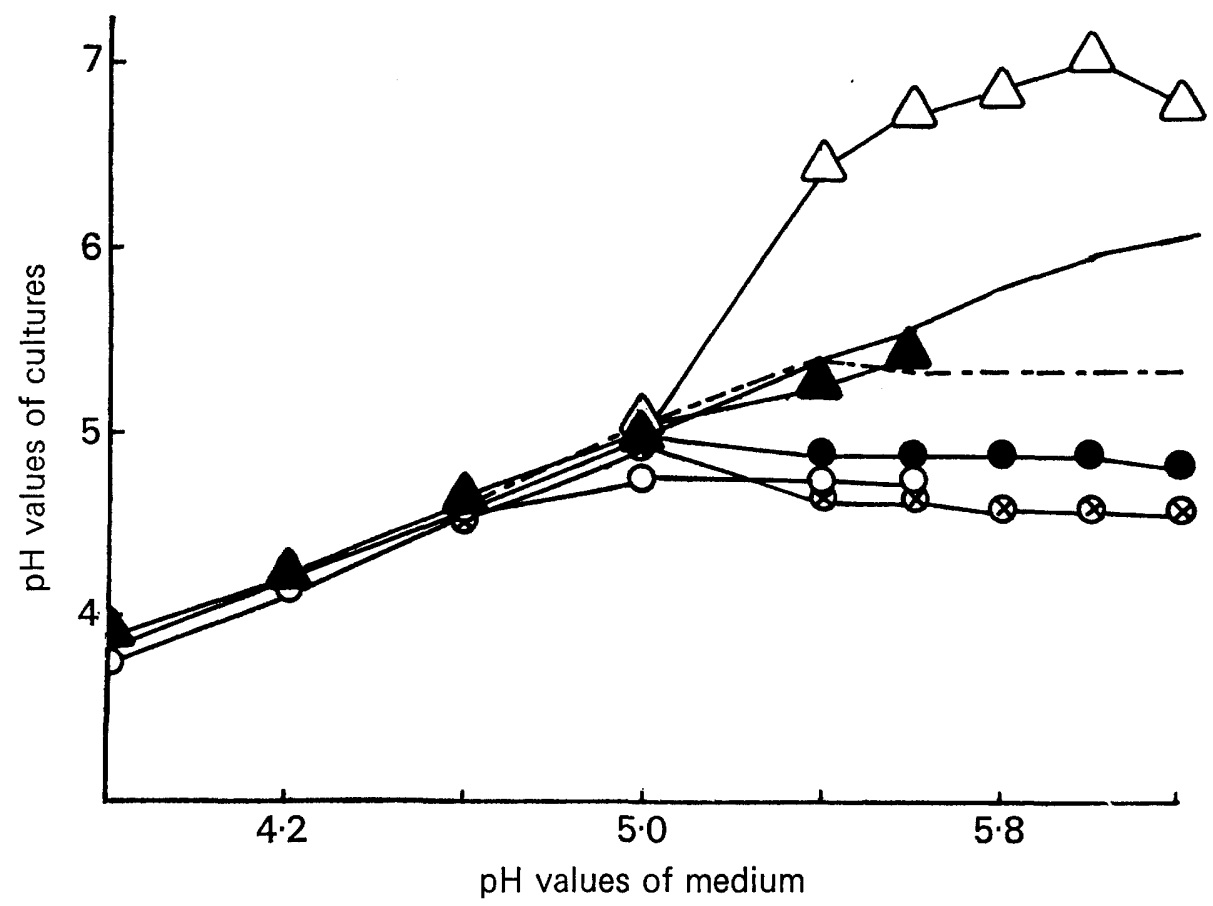

FIG. 7.-Initial $p \mathrm{H}$ of unbuffered medium: - compared with the final $p \mathrm{H}$ values of 48 -h cultures of gram-negative organisms:

$\otimes-\otimes$ Salm. typhimurium;

$O$ E. coli; $\Lambda-\Delta$ bacteroides; $\triangle \longrightarrow \triangle P$. aeruginosa; Shig. sonnei; - - - V. cholerae El Tor.

retarded growth occurred, the $p \mathrm{H}$ values of most of the cultures fell slightly below those of the uninoculated media (fig. 5), but at initial $p \mathrm{H}$ values below 5.8 the final culture was the same.

\section{Growth of gram-negative organisms in unbuffered media}

Viable counts. In terms of the viable count after 24 hours' incubation, unbuffered medium had no bacteristatic effect upon the growth of $E$. coli when the initial $p \mathrm{H}$ of the medium was greater than 4.6. Salm. typhimurium showed uninterrupted growth above $p \mathrm{H} 5.0$ whereas Shig. sonnei and $V$. cholerae $\mathrm{El}$ Tor failed to grow at $p \mathrm{H} 5.0$ and $p \mathrm{H} 5.4$ respectively (fig. 6). $P$. aeruginosa, $V$. cholerae $\mathrm{El}$ Tor and bacteroides which failed to grow below $p \mathrm{H} 5.6$ produced unretarded growth above these values. All the gram-negative organisms tested under these conditions produced counts of $10^{6}$ per $\mathrm{ml}$ or greater at $p \mathrm{H} 5.6$ except for bacteroides and $V$. cholerae $\mathrm{El}$ Tor.

$p H$ values. The bacterial growth had little effect upon the $p \mathrm{H}$ values of cultures at an initial $p \mathrm{H}$ of 4.6 and below. Above this initial $p \mathrm{H}$ value, however, cultures became markedly acidic, with the exception of those inoculated with $P$. aeruginosa (fig. 7); from a starting $p \mathrm{H}$ of greater than $5 \cdot 0$, the $p \mathrm{H}$ values of these cultures rose to $p \mathrm{H} \mathrm{7.0}$ after 48 hours' incubation. At the other extreme, 


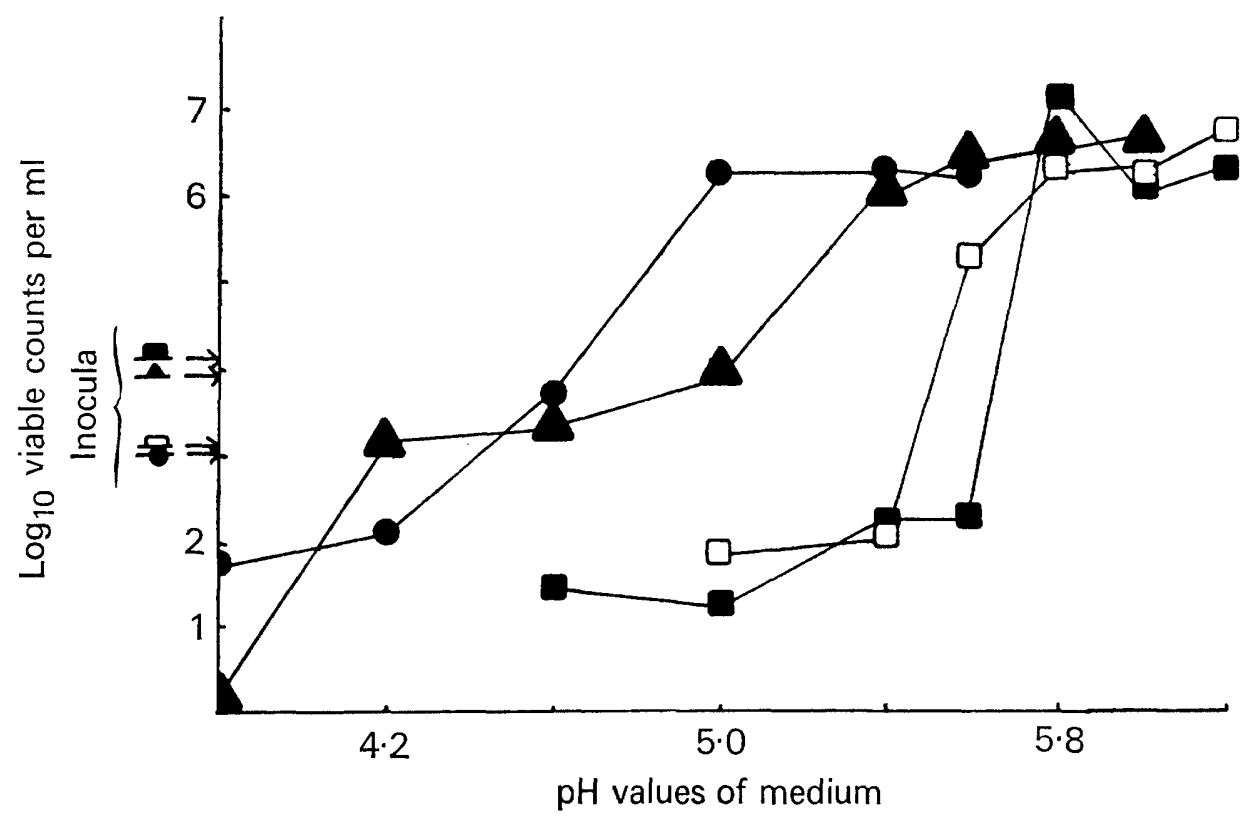

FIG. 8.-Average of mean viable counts of gram-positive organisms in buffered medium after 24 hours' incubation: perfringens; bifidobacteria; Clostridium paraputrificum.

cultures of $E$. coli grew sufficiently between $p \mathrm{H} 5.0$ and 5.6 to give a final $p \mathrm{H}$ value of $4 \cdot 7$ after 48 hours' incubation.

\section{Growth of gram-positive organisms in acetate-buffered medium}

Viable counts. The acetate-buffered medium had little or no effect upon the multiplication of bifidobacteria and Strept. faecium. The bifidobacteria showed unimpeded growth at $p \mathrm{H}$ values above $4 \cdot 6$, reaching viable counts above $10^{6}$ per $\mathrm{ml}$ at $p \mathrm{H} 5.0$ in $24 \mathrm{~h}$. Strept. faecium followed a similar pattern reaching counts above $10^{6}$ per $\mathrm{ml}$ at $\mathrm{pH} 5.4$ in $24 \mathrm{~h}$. The clostridia, on the other hand, showed no growth at $p \mathrm{H} 5.4$ and lower, but multiplication was rapid above this value, counts above $10^{6}$ being reached in $24 \mathrm{~h}$ (fig. 8).

$p H$ values. In acetate-buffered media the growth of bifidobacteria had a marked effect upon the $p \mathrm{H}$ value. Above the starting $p \mathrm{H}$ value of $4 \cdot 6$, the final $p \mathrm{H}$ of the cultures after 48 hours' incubation was 4.8 or below (fig. 9). Cultures of Strept. faecium behaved similarly but were less effective in reducing the $p \mathrm{H}$ of the media; the clostridia were least effective.

\section{Growth of gram-positive organisms in unbuffered medium}

Viable counts. Medium without acetate buffer had no effect upon the growth

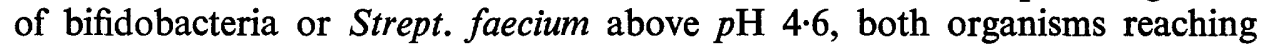
counts above $10^{6}$ per $\mathrm{ml}$ in $12 \mathrm{~h}$. The growth of $C$. paraputrificum and $C$. 


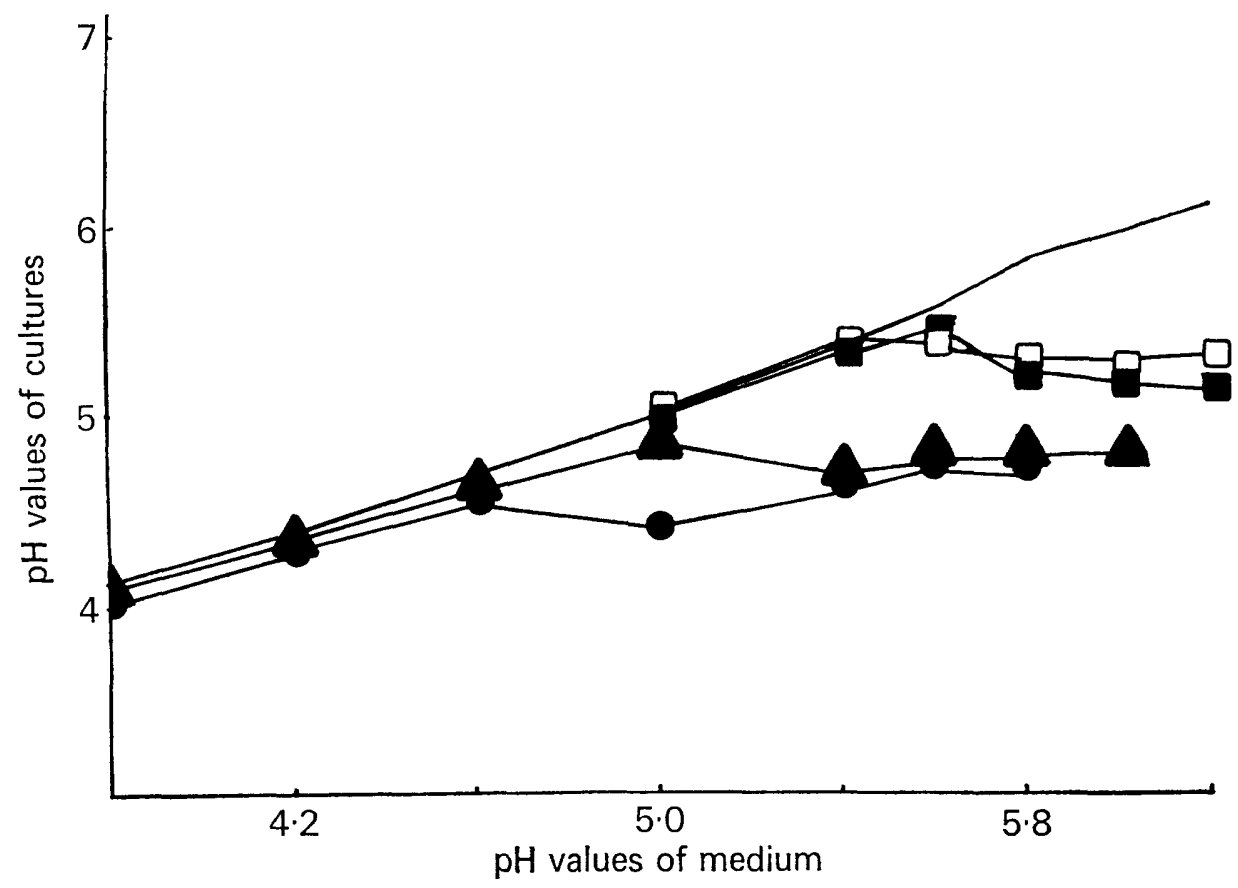

FIG. 9.-Initial $p \mathrm{H}$ of buffered medium: $\_$, compared with the final $p \mathrm{H}$ values of $48-\mathrm{h}$ cultures of gram-positive organisms: - bifidobacteria;

C. perfringens; $\square \longrightarrow \square$ C. paraputrificum

perfringens was inhibited below $p \mathrm{H} 4.8$ and 5.6 respectively, but at higher values the growth of both organisms was unimpeded (fig. 10).

$p H$ values. Growth in unbuffered media produced $p \mathrm{H}$ values that reflected the ability of the gram-positive organisms to grow from an initial $p \mathrm{H}$ above $4 \cdot 6-5 \cdot 0$. The final values of all the $48 \mathrm{~h}$ cultures remained below $5 \cdot 0$ (fig. 11).

\section{Discussion}

Chromatographic analysis of the metabolites produced in vitro by saccharolytic organisms that are commonly encountered in the faeces of the breast-fed infant showed that varying quantities of acetic acid accumulated when the bacteria were grown in the presence of a fermentable sugar. The acid appeared in both the free and combined form during the anaerobic growth of $E$. coli and bifidobacteria. These findings reflect the in-vivo observations made by Bullen et al. (1976) on the chromatographic analysis of faeces from breast-fed infants. The growth of Strept. faecium contributed even more free acetic acid to the faecal environment so that the combined effect of the growth of the saccharolytic bacteria was to produce an acetate buffer at a low $p \mathrm{H}$.

Anaerobic incubation of cultures in the presence of acetate buffer had one of three effects on bacterial growth, depending on the organism and the $p \mathrm{H}$ 


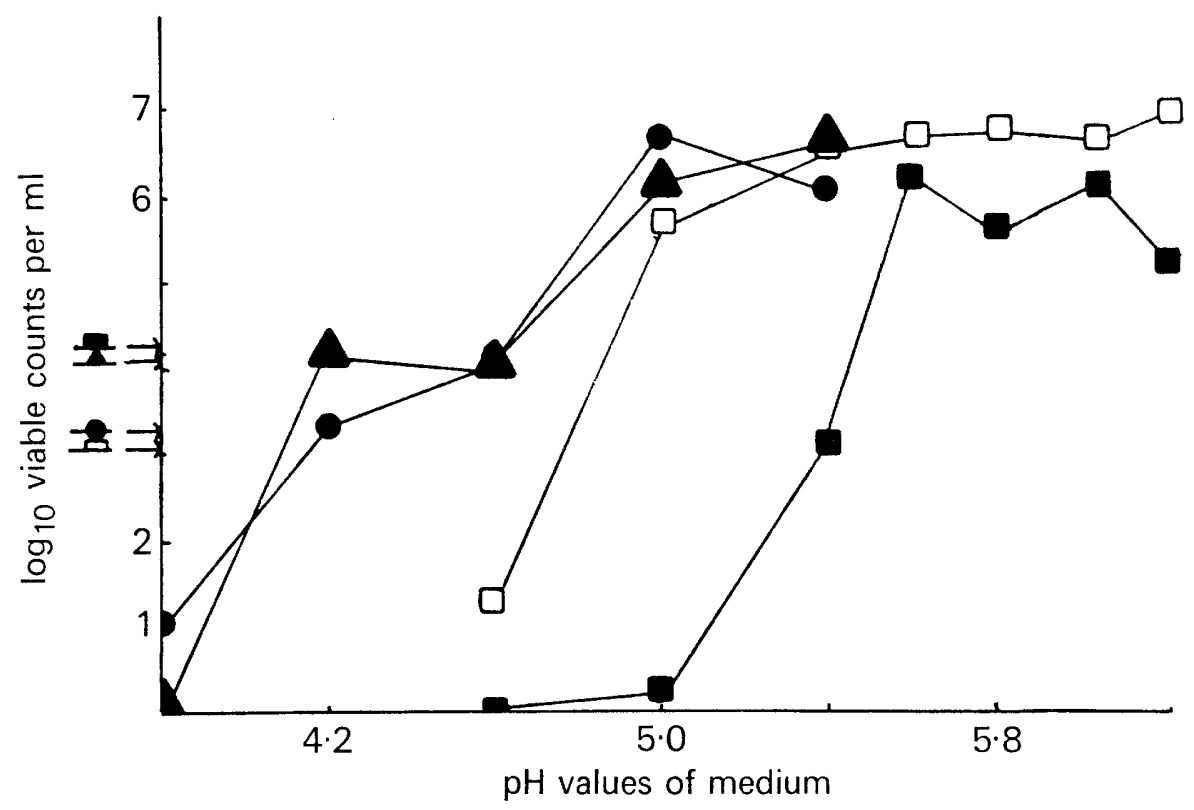

FIG. 10.-Average of mean viable counts of gram-positive organisms in unbuffered medium after 24 hours' incubation: perfringens; C. paraputrificum.

range of the culture; bacteria were killed, growth was prevented, or the generation rate was retarded. These effects were greater upon the growth of gramnegative organisms than upon that of bifidobacteria and Strept. faecium (figs $4 b$, and 8). In the breast-fed infant, faecal material commonly showed $p \mathrm{H}$ values within this range (Bullen, et al., 1976) with the viable counts of bifidobacteria and Strept. faecium relatively high compared with those of E. coli. The clostridia were susceptible to the bacteristatic effect of the buffer within the $p \mathrm{H}$ range 4.6-5.6, which would account for the absence or relatively low counts of these organisms in the faeces of the breast-fed infant.

It seems reasonable to suggest that the presence of lactoferrin and antibody in the colostrum, and in the early milk, plays an important role in the initial protective mechanism of the infant against the multiplication of gram-negative organisms. As the concentration of lactoferrin in the milk declines, and the bifidobacillary flora and the buffer are established in the large intestine, the protective role against gram-negative bacteria is taken over by the buffered acidic environment.

It is well known that other organic acids, such as formic and lactic acids are present in faecal material, and no doubt they too play a part in maintaining a balanced environment in the large intestine. Should the diet be changed to a cows' milk preparation in which the phosphorus and protein content are relatively high and the lactose low, the buffer quickly disappears resulting in a rapid outgrowth of the gram-negative and putrefactive organisms. 


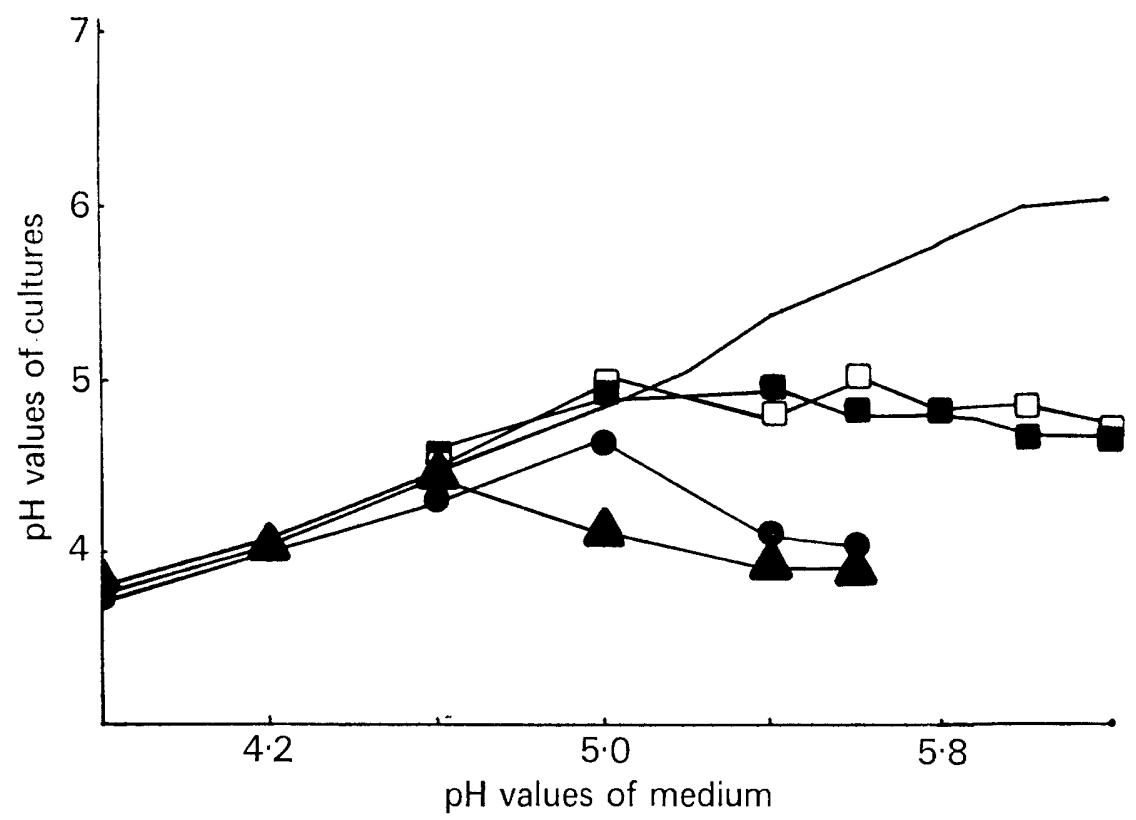

FIG. 11.-Initial $p \mathrm{H}$ of unbuffered medium: - , compared with the final $p \mathrm{H}$ values of 48-h cultures of gram-positive organisms:

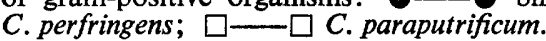

\section{SUMMARY}

In-vitro studies showed that a number of factors are likely to influence the production and maintenance of a bifidobacillary flora and low $p \mathrm{H}$ in the faeces of newborn infants. Considerable importance is attached to the nature of the end products of bacterial metabolism in the large intestine. Thus, there is evidence to suggest that acetic acid and other metabolites of intraluminal bacterial growth suppress the growth of gram-negative organisms, but are without effect upon that of bifidobacteria. This mechanism in turn is controlled by the nature of the feed; important factors in breast milk include high lactose, low protein and low phosphate content.

We are greatly indebted to $\operatorname{Dr} \mathrm{A}$. T. Willis for his advice and continued interest in the work. We wish to thank Mrs K. Williams and Mrs D. Jarrard for their invaluable technical assistance, and Mr J. Harrison, A.R.P.S., and Miss Frankland for the photographic reproduction of the figures.

\section{REFERENCES}

Beerens, H., Schaffner, Y., Gulllaume, J. ANd Castel, M. M. 1963. Les bacilles anaérobies non sporulés a Gram-négatif favorisés par la bile. Leur appartenance au genre Eggerthella (nov. gen.). Annls Inst. Pasteur, Lille, 14, 5.

Bullen, C. L., Tearle, P. V. AND Willis, A. T. 1976. Bifidobacteria in the intestinal tract of infants: an in-vivo study. J. med. Microbiol., 9, 327.

Cruickshank, R., Duguid, J. P., Marmion, B. P. and Swain, R. H. A. 1975. Medical microbiology, vol. 2, The practice of medical microbiology, 12th ed., Edinburgh, p. 88. 
Holdeman, L. V. AND MooRe, W. E. C. 1972. Anaerobe laboratory manual, Viriginia Polytechnic Institute and State University Anaerobe Laboratory, Blacksburg.

Miles, A. A., MisRA, S. S. AND IRWIN, J. O. 1938. The estimation of the bactericidal power of the blood. J. Hyg., Camb., 38, 732.

OxoId MANUAL OF CULTURE MEdia, INGREDIENTS AND OTHER LABORATORY SERVICES 1973. 3rd ed., London, p. 199.

Willis, A. T., Bullen, C. L., Williams, K., FaGG, C. G., Bourne, A. And Vignon, M. 1973. Breast milk substitute. A bacteriological study. Br. med.J., 4, 67. 